DOI: $10.5272 /$ jimab.2013191.423

\title{
THE METHOD OF BIPLANE DOUBLE- SUPPORTED SCREW FIXATION (BDSF) AT FEMORAL NECK FRACTURES - PRINCIPLE AND CLINICAL OUTCOMES.
}

\author{
Orlin Filipov \\ Department of Geriathic orthopedics, Vitosha Hospital, Sofia, Bulgaria
}

\begin{abstract}
The current work is given over to the particular purpose of revealing the principle and clinical outcomes of the novel method of Biplane double-supported screw fixation (BDSF), introduced in our Department of Geriatric Orthopedics in 2007. BDSF is a new method of internal fixation, designed to improve the internal fixation strength at intracapsular femoral neck fractures in the presence of osteoporosis, according to an original concept of the establishment of two supporting points for the implants and their biplane positioning in the femoral neck and head. The provision of two steady supporting points for the implants and the highly increased (obtuse) angle at which they are positioned, allow the body weight to be transferred successfully from the head fragment onto the diaphysis thanks to the strength of the screws, with the patient's bone quality being of least importance. The position of the screws allows them to slide under stress with a minimal risk of displacement.

The method was developed in search of a solution for those patients, for whom primary arthroplasty is contraindicated.
\end{abstract}

Key words: femoral neck fixation; intracapsular fractures; osteoporotic fractures; hip; BDSF; F-technique

\section{INTRODUCTION}

At present, in active elderly patients with displaced femoral neck fractures, the total hip replacement (THR) is a golden standard. However, there are also patients with high operative risk for a large surgical intervention, defined by the presence of comorbidities and the arthroplasty procedure with these patients is contraindicated.

The angular, spiral shape of the proximal femur exposes the femoral neck to powerful shearing, and especially bending and torsion forces. Under the conditions of severe osteoporosis, the femoral neck consists of cortical walls, enveloping soft cancellous bone, having unimportant mechanical significance, and the neck can often be looked biomechanically as a hollow cylinder. If the condition of patient is not appropriate for total hip replacement (mental diseases or cardiopulmonary risks), and a decision is made for a screw fixation, the implanted screws must be solidly fixed in the distal fragment on at least two supporting points in order to provide resistance to the shearing forces in case of osteoporosis. The traditional screw fixation methods, however, do not meet the above-named requirement. Present-day popular traditional methods of femoral neck fixation, which are performed by three cancellous screws, placed parallel to each other and parallel to the femoral neck axis, are associated with poor outcomes in 20 to $48 \%$ (Asnis 1994 [1], Lu-Yao 1994 [2], Tidermark 2003[3], Blomfeldt 2005[4], Rogmark 2006[5], Gjertsen 2010 [6].

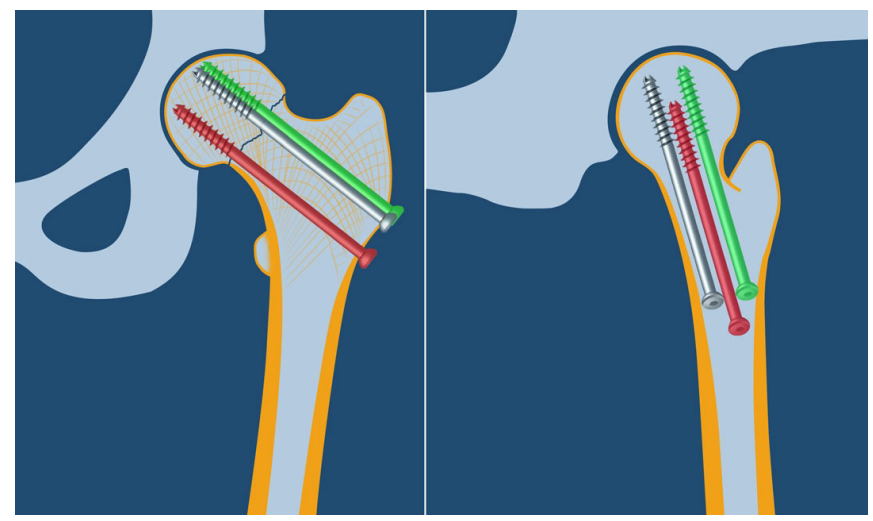

Fig. 1. A conventional method.

The new method of Biplane double-supported screw fixation (BDSF) increases the fixation strength by its innovative concept of biplane positioning of the three screws, which makes it possible for the screws to be placed at an increased angle, so they to lean on two solid supporting points [7] (Fig.2). 


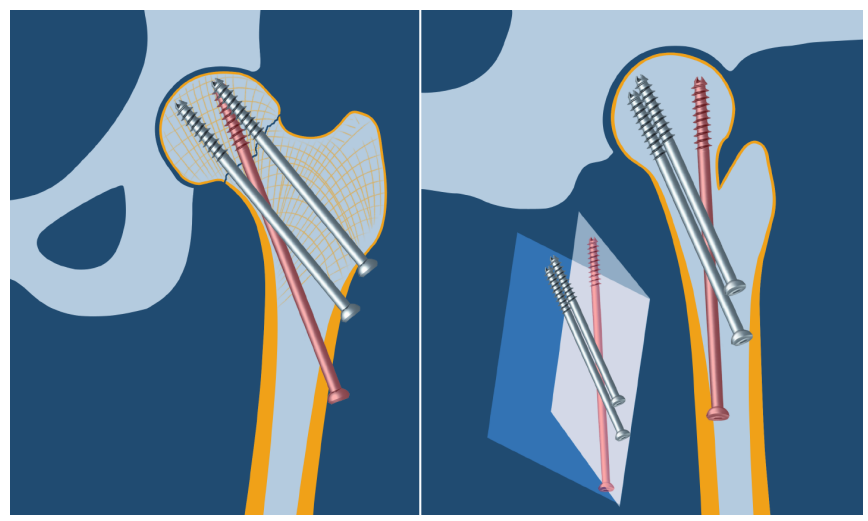

Fig. 2. The new method of Biplane Double-supported Screw Fixation (BDSF)

a.) A-P view; b.) Lateral view

The BDSF-method has two calcar-buttressed implants. The distal screw (red color) touches on the calcar in the lateral part of the femoral neck (Fig.2a), and also in the middle part of the femoral neck this screw has a cortical support on the posterior cortex of the neck (Fig. 2b). The middle screw (white color) touches on the calcar in the middle part of the neck (Fig. 2a).

At the method of BDSF, the innovative position of the three screws, laid in two planes (in lateral view), makes it possible for the entry points of two of the implants to be placed much more distally, in the solid cortex of the proximal diaphysis, and also to lean onto the femoral neck distal cortex.

Thus we establish two supporting points. The solid cortex of the calcar acts as a medial supporting point for the screws - supporting point $\mathbf{A}$. This supporting point works under pressure.

The entry points of the distal and the middle screws in the solid cortex of the proximal diaphysis, acts as a lateral supporting point for the two screws - supporting point $\mathbf{B}$. This supporting point works under pressure in proximal direction.

The position of the distal screw as well as the middle screw thus achieved by the method, in terms of statics, turns them into a simple beam with an overhanging end, loaded with a vertical force. This beam with an overhanging end, bridging the fracture, successfully supports the head fragment, bearing the body weight and transferring it to the diaphysis, resisting to the shearing forces (in a standing position).
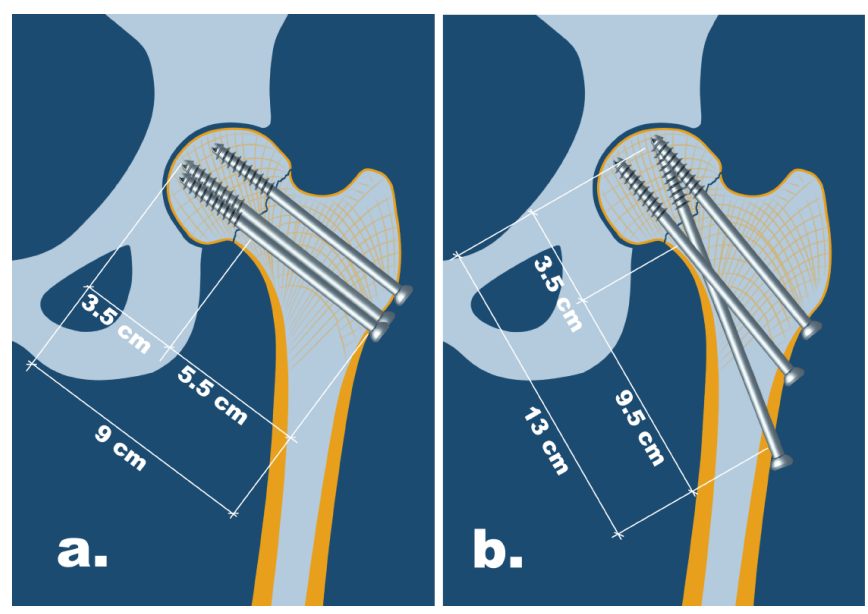

Fig. 3. Biplane Double-supported Screw Fixation (BDSF), a scheme.

The mean distances. (Redrawn from: Filipov O. Biplane double-supported screw fixation (F-technique): a method of screw fixation at osteoporotic fractures of the femoral neck. Eur J Orthop Surg Traumatol. 2011; Oct; 21(7):539-543). [7]

In the sagital plane (in lateral view) the distal screw is touched on the posterior cortex of the femoral neck, thus ensuring a posterior supporting point, which works under pressure in posterior direction, in the process of anteroposterior bending of the neck (when rising from a chair).

Other advantages of the method are: (1) Due to the biplane placement, enough space for a third screw is provided, unlike the classical authors' methods, where just one or a maximum of two implants are placed at an obtuse angle (Brittain 1942[8], Burns 1944[9], Kьntscher 1953[10], Garden 1961[11], von Bahr 1974[12]). (2) due to the increase in the distance between the two supporting points, the weight borne by the bone is reduced. (3) The entry points of the screws are positioned wide apart from each other, which ensures that when weight bearing, the tensile forces spread over a greater surface of the lateral cortex and thus the risk of a subtrochanter fracturing decreases significantly. (4) The screw, placed at a highly increased angle, works in a direction close to the direction of the loading force, which guarantees better results for the screw in its role of a beam because of the influence of its sagging decreases. (5) Very important advantage for BDSF is that the distal screw is touched on the posterior cortex, which together with the highly increased angle of this screw, provides improved strength of fixation at antero-posterior bending of the neck, a thesis confirmed experimentally (Walker 2007[13]). 


\section{The method of Biplane Double-supported Screw fixation (BDSF) \\ Indications:}

Fractures of the Garden types from I to IV. The indications and contraindications for application of the BDSF-method are generally the same as of the conventional methods for fixation of the femoral neck fractures. The BDSF-method significantly expands the indications for application of screw fixation in terms of the bone, changed by osteoporosis. The method is most useful and has no reasonable alternative in adult patients above 80 years with a high cardiopulmonary risk, as in patients with severe concomitant diseases, inclusively some mental diseases, patients with senile dementia, and others, for which the primary joint replacement may be contraindicated.

Implants: $7.3 \mathrm{~mm}$ self-tapping cannulated screws

Reduction: Mild traction, slight abduction and internal rotation of the limb are applied. Only anatomical reduction is acceptable.

Biplane Double-supported Screw fixation (BDSF) operative technique [7]

Approach. A straight lateral incision, starting at the level of the lower border of the greater trochanter, with distal length of 6 to $10 \mathrm{~cm}$. A stripping of the periosteum of the lateral diaphysis at $6-7 \mathrm{~cm}$ is performed.

Via the concept of biplane positioning, developed by the BDSF, the three screws are placed in two vertical diverging planes (in lateral view). The distal screw is laid in the dorsal oblique plane, the middle and proximal screws are placed in the ventral oblique plane (Fig.2b).

Firstly, we lay the guiding wire for the distal cannulated screw. Its entry point is at $5-7 \mathrm{~cm}$ distally from the lower border of the greater trochanter, in the lateral surface of the diaphysis. The wire is directed proximally at an angle of $150-165^{\circ}$ towards the diaphyseal axis, with inclination to posteriorly-proximally, so that after it touches onto the curve of the distal femoral neck cortex (the "calcar") tangentially, the wire goes into the dorsal third of femoral head. Thus the wire also comes naturally in contact with the posterior neck cortex.

The middle guiding wire is placed second. The entry point, depending on the CCD-angle, is at 2 to $4 \mathrm{~cm}$ proximally from the distal wire. This wire is placed at an angle of $135-140^{\circ}$ towards the diaphyseal axis and is inclined to anteriorly-proximally, so that after it touches onto the calcar tangentially, the wire goes into the frontal one-third of the femoral head (in lateral view) and into the distal one-third of the femoral head (in A-P view).

Then we place the proximal guiding wire, with its entry point at $1.5-2 \mathrm{~cm}$ proximally from the middle wire and parallel to it. The latter wire goes into the front one-third of the femoral head (in lateral view) and into the proximal onethird of the femoral head, in A-P view. Measuring of the lengths and drilling with a $5.0 \mathrm{~mm}$ cannulated reamer follow.
The middle and proximal screws are placed first because they are perpendicular to the fracture surface. Before placing the middle and distal screws, we overdrill their holes in the lateral cortex by using a $7.0 \mathrm{~mm}$ cannulated reamer, where a bone tap is difficult to be used. Next we release the foot traction, and by hammering on a plastic impactor on the diaphyseal cortex, a several-time impaction of the fracture with an additional tightening up of the screws follows. Finally, the distal screw is placed. The wire tip is guided into the desired direction by the operator's free hand with the help of a cannulated instrument.

When we place a guiding wire through the thick cortex of the diaphysis, it can go in a wrong direction, into the medial diaphyseal cortex distally from the femoral neck (in A-P view) or into the cortex of the neck (in lateral view). Than we have to take out the wire completely and after a change in its direction, by the high-speed rotating trocar tip, we have to change the direction of the canal in the cortex or we have to bore a new hole next to it, which is true for all other methods of internal fixation of the femoral neck. Sometimes in a dense bone, a release from the thick lateral cortex is required and if the entry point of the wire is correctly chosen, we ream around the guide wire placed in a poor position by the $5.0 \mathrm{~mm}$ cannulated reamer. Thus in the created opening the wire is freed from its contact with the lateral cortex and is easily directed in the necessary direction. In the reamed hole "with a correctly chosen point of entry the nail (the wire) is self-locating" (Garden 1961). The guide wire should be thick not less than $2.0-\mathrm{mm}$. When using a standard instrument set for $7.3-\mathrm{mm}$ screws of "Synthes", such a problem of a difficult location is practically absent, because its guiding wires are $2.8-\mathrm{mm}$ thick and are not changing their direction even in the thick diaphyseal cortex.

The placing of screws at a very oblique angle requires following of the principle of their two-plane positioning and none of the screws must be placed in the central zone of the neck in lateral view. The distal screw plays a role of a beam with overhanging end and can not be tightened so hard. Because it is placed at a very oblique angle, if it is tightened excessively, it can, in some rare cases, cause longitudinal fissura. Such a fissura does not weaken the fixation, because the tubular form of the diaphysis acts as a type of spring against that fissura. In this case the distal screw must be unscrewed at one turnover.

Aftertreatment. Young patients: limited weight bearing for 2-4 months, by using two crutches. Demented patients: immediate full weight bearing. Prevention of selfharming or removing the sterile dressing. 

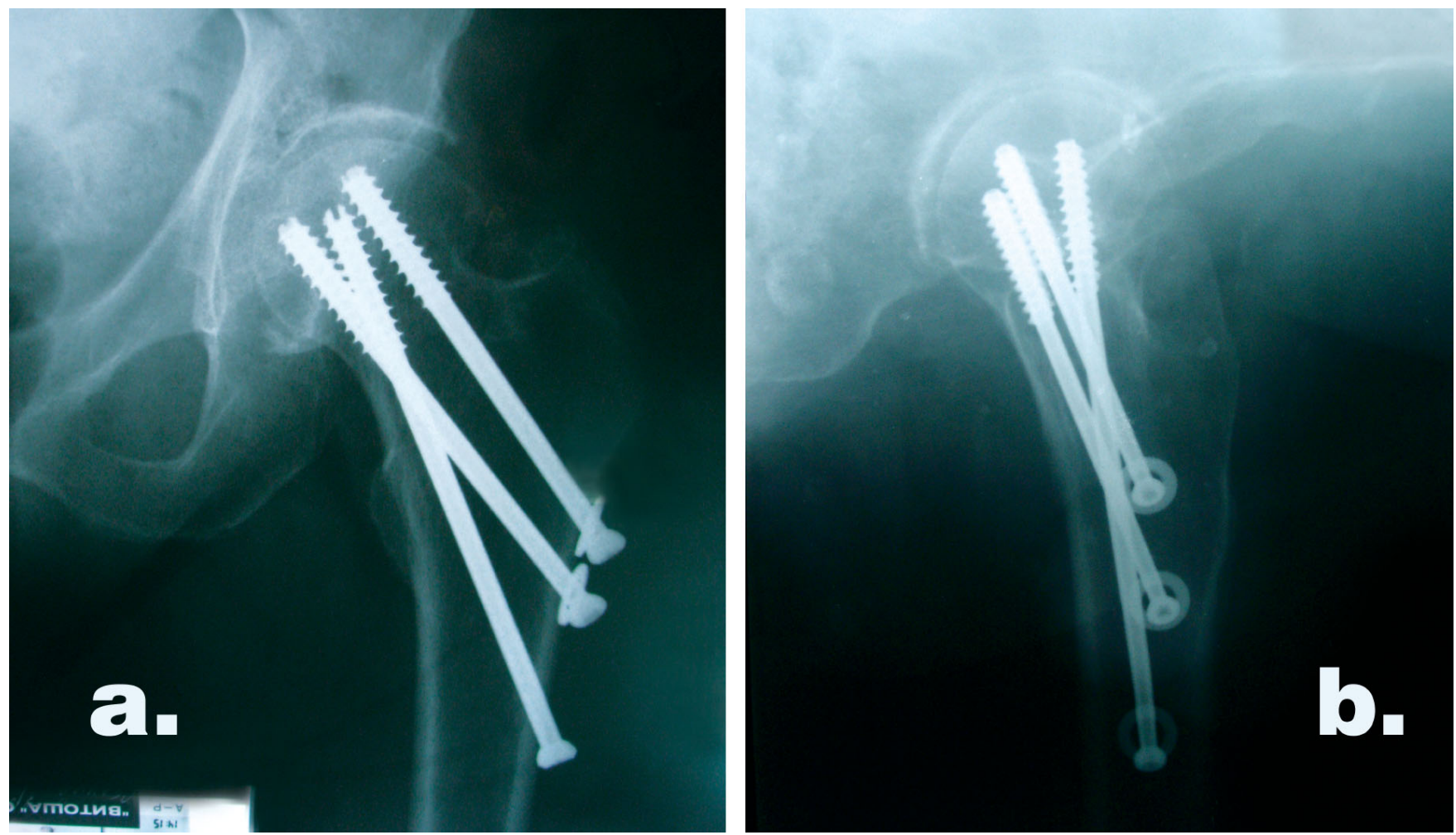

Fig. 4. Radiography of the BDSF-method. a. Anteroposterior view; b. Lateral view. (Redrawn from: Filipov O. Biplane double-supported screw fixation (F-technique): a method of screw fixation at osteoporotic fractures of the femoral neck. Eur J Orthop Surg Traumatol. 2011; Oct; 21(7):539-543). [7]

\section{CLINICAL RESULTS}

From a series of 178 operated patients, 88 were studied [7]. Out of the 88 studied patients,

$27(30.68 \%)$ are male and $61(69.31 \%)$ female; the average age is 76.9 (with the youngest patient aged 38 and the oldest aged 99$)$. Grouping patients by age: 18 patients $(20.45 \%)$ are under $69 ; 27$ patients $(30.68 \%)$ are aged $70-79$; 37 patients $(42.04 \%)$ are aged $80-89 ; 5$ patients $(5.68 \%)$ are aged $90-95 ; 1$ patient $(1.13 \%)$ is aged $95-100$. More than one accompanying diseases, which influence the results of Harris hip score, were found in 21 patients $(23.86 \%)$. The average follow-up period is 8.06 months.

The fractures have been classified by the Garden classification as follows:

Garden type I: 3(3.41\%); Garden type II: 1(1.14\%); Garden type III: 9(10.23\%); Garden type IV: 75(85.02\%).

Results. From the studied 88 patients fracture union was registered in 87 patients $(98.86 \%)$ and failure in 1 patient $(1.13 \%)$.

Assessment according to the Harris hip score (modified): poor results - in 10 patients $(11.36 \%)$. Fair results - in 20 patients $(22.72 \%)$. Good results - in 21 patients (23.86\%). Excellent results - in 37 patients (42.04\%). [14].

\section{DISCUSSION}

The present state of knowledge reveals, that in terms of the screw positions in the femoral neck, there is a large divergence of views.

Many authors recommend placement of the distal implant touched on the distal cortex of the femoral neck (or the „calcar") (Burns 1944 [9], Kuntscher 1953 [10], Garden 1961 [11], von Bahr 1974 [12], Hogh 1982 [15], Paus 1986 [16], Rehnberg 1989 [17], Lindequist 1993 [18], Parker 2002 [19], Lykke 2003 [20], etc.).

Some authors recommend central placement of the screws in lateral view (Paus 1986 [16], Rehnberg 1989 [17]).

Others recommend peripheral placement of the screws (Booth 1998 [21]) and ensuring of a posterior cortical support (von Bahr 1974 [12], Lindequist 1993 [18], Lagerby 1998 [22]). Many authors insist that the screws have to be parallel (von Bahr 1974 [7], Hogh 1982 [15], Paus 1986 [16], Medsen 1987 [23], Elmerson 1988 [24], Rehnberg 1989 [17], Lindequist (1993) [18], Asnis 1994 [1], Lagerby 1998 [22]).

However, the dictum of parallel screw placement is not proven (Parker 2002 [19]) and some authors recommend spreading of the screws in lateral view (Lykke 2003 [20], Gurusamy 2005 [25]). Some techniques has been abandoned (low-nail, cross-screw, multiple pin) and others are used rarely (the two-screw fixation). In the present, a fixation by 
three cannulated A.O. screws is widely used. The inverted triangle configuration is usually preferred, as it provides greater strength (Mizrahi 1980 [26], Swiontkowski 1987 [27]), compared to the upright triangle, diamond pattern, linear vertical, and linear horizontal configuration. The screws placed under increased angle demonstrate better fixation strength (Walker 2007 [13]).

\section{CONCLUSIONS}

With the BDSF-method through the concept of biplane positioning of the three screws, the provision of two steady supporting points for the implants and the obtuse angle at which they are positioned, allow the body weight to be transferred successfully from the head fragment onto the diaphysis thanks to the strength of the screws, with the patient's bone quality being of least importance. The position of the screws allows them to slide under stress at a minimal risk of displacement. The achieved results with the BDSF method in terms of fracture consolidation are far more successful than the results with conventional fixation methods. The BDSF-method ensures reliable fixation, early rehabilitation and excellent long-term outcomes, even in non-cooperative patients. BDSF is mainly addressed to patients, who have contraindications for arthroplasty, as well as for a conventional screw fixation.

Acknowledgments: No institutional funding or grants as well as technical assistance or contributions of this research has been obtained by the author.

\section{REFERENCES:}

1. Asnis SE, Wanek-Sgaglione L. Intracapsular fractures of the femoral neck. Results of cannulated screw fixation. J Bone Joint Surg Am. 1994 Dec 01;76(12):1793-1803. [PubMed]

2. Lu-Yao GL, Keller RB, Littenberg B, Wennberg JE. Outcomes after displaced fractures of the femoral neck. A meta-analysis of one hundred and six published reports. J Bone Joint Surg Am. 1994 Jan; 76(1):15-25. [PubMed]

3. Tidermark J, Ponzer S, Svensson $\mathrm{O}$, Sцderqvist A, Tцrnkvist H. Internal fixation compared with total hip replacement for displaced femoral neck fractures in the elderly. $J$ Bone Joint Surg Br. 2003 Apr;85-B(3):380-388. [PubMed] [CrossRef]

4. Blomfeldt R, Tornkvist H, Ponzer $\mathrm{S}$, Soderqvist A, Tidermark J. Internal fixation versus hemiarthroplasty for displaced fractures of the femoral neck in elderly patients with severe cognitive impairment. J Bone Joint Surg Br. 2005 Apr;87-B(4):523-529. [PubMed] [CrossRef]

5. Rogmark C, Johnell O. Primary arthroplasty is better than internal fixation of displaced femoral neck fractures: a meta-analysis of 14 randomized studies with 2,289 patients. Acta Orthop. 2006 Jun;77(3): 359-367. [PubMed] [CrossRef]

6. Gjertsen JE, Vinje T, Engesaeter LB,
Lie SA, Havelin LI, Furnes O, et al. Internal screw fixation compared with bipolar hemiarthroplasty for treatment of displaced femoral neck fractures in elderly patients. J Bone Joint Surg Am. 2010 Mar;92(3):619-628. [PubMed] [CrossRef]

7. Filipov O. Biplane doublesupported screw fixation (F-technique): a method of screw fixation at osteoporotic fractures of the femoral neck. Eur J Orthop Surg Traumatol. 2011 Oct;21(7):539-543. [PubMed] [CrossRef]

8. Brittain HA. The low nail. $\mathrm{Br}$ Med J. 1942 Apr 11;1(4240):463-464. [PubMed]

9. Burns BH, Young RH. Early movement in the treatment of closed fractures. Lancet. 1944 Jun; 243(6301): 723-725. [CrossRef]

10. Kuntscher G. [Fully automatic nailing of the femoral neck]. [in German] Z Orthop Ihre Grenzgeb. 1953; 84(1):1728. [PubMed]

11. Garden RS. Low-angle fixation in fractures of the femoral neck. $J$ Bone Joint Surg Br. 1961 Nov;43-B(4):647-663.

12. von Bahr V, Syk B, Walheim G. Osteosynthesis of femoral neck fracture using screws. Acta Chir Scand. 1974; 140(4):277-282. [PubMed]

13. Walker E, Mukherjee DP, Ogden AL, Sadasivan KK, Albright JA. A biomechanical study of simulated femoral neck fracture fixation by cannulated screws: effects of placement angle and number of screws. Am J Orthop (Belle Mead NJ). 2007 Dec;36(12): 680-684. [PubMed]

14. Harris WH. Traumatic arthritis of the hip after dislocation and acetabular fractures: treatment by mold arthroplasty. An end-result study using a new method of result evaluation. $J$ Bone Joint Surg Am. 1969 Jan; 51A(4): 735-755. [PubMed] Modified, Canale ST, Beaty J. Campbell's operative orthopaedics, $11^{\text {th }}$ ed., Mosby 2007.

15 , Hogh J, Jensen J, Lauritzen J. Dislocated femoral neck fractures: a follow-up study of 98 cases treated by multiple AO (ASIF) cancellous screws. Acta Orthop Scand. 1982 Apr;53(2):2459. [PubMed]

16. Paus A, Gjengedal E, Hareide A, Jorgensen JJ. Dislocated fractures of the femoral neck treated with von Bahr screws or hip compression screw: results of a prospective, randomized study. J Oslo City Hosp. 1986 MayJun;36(5-6):55-61. [PubMed]

17. Rehnberg L, Olerud C. The stability of cervical hip fractures and its influence on healing. J Bone Joint Surg Br. 1989 Mar; 71-B(2):173-177. [PubMed]

18. Lindequist S. Cortical screw support in femoral neck fractures. A 
radiographic analysis of 87 fractures with a new mensuration teqhnique. Acta Orthop Scand. 1993 Jun;64(3):289-293. [PubMed]

19. Parker MJ, Tagg CE. Internal fixation of intracapsular fractures. $J R$ Coll Surg Edinb. 2002 Jun;47(3):541547. [PubMed]

20. Lykke N, Lerud PJ, Stromsoe K, Thorngren KG. Fixation of fractures of the femoral neck: a prospective, randomised trial of three Ullevaal hip screws versus two Hansson hook-pins. J Bone Joint Surg Br. 2003 Apr;85(3): 426-430. [PubMed] [CrossRef]

21. Booth KC, Donaldson TK, Dai QG. Femoral neck fracture fixation: a biomechanical study of two cannulated screw placement techniques. Orthopedics. 1998 Nov;21(11):11731176. [PubMed]
22. Lagerby $\mathrm{M}$, Asplund S, Ringqvist I. Cannulated screws for fixation of femoral neck fractures: no difference between Uppsala and Richards screws in a randomized prospective study of 268 cases. Acta Orthop Scand. 1998 Aug;69(4):387-91. [PubMed]

23. Madsen F, Linde F, Andersen E, Birke H, Hvass I, Poulsen TD. Fixation of displaced femoral neck fractures: a comparison between sliding screw plate and four cancellous bone screws. Acta Orthop Scand. 1987 Jun;58(3):212-16. [PubMed]

24. Elmerson S, Andersson GB, Irstam L, Zetterberg C. Internal fixation of femoral neck fracture: no difference between the Rydell four-flanged nail and Gouffon's pins. Acta Orthop Scand. 1988 Aug;59(4):372-6. [PubMed]
25. Gurusamy K, Parker MJ, Rowlands TK. The complications of displaced intracapsular fractures of the hip: the effect of screw positioning and angulation on fracture healing. $J$ Bone Joint Surg Br. 2005 May;87(5):632-634. [PubMed] [CrossRef]

26. Mizrahi J, Hurlin RS, Taylor JK, Solomon L. Investigation of load transfer and optimum pin configuration in the internal fixation, by Muller screws, of fractured femoral necks. Med Biol Eng Comput. 1980 May;18(3):319325. [PubMed]

27. Swiontkowski MF, Harrington RM, Keller TS, Van Patten PK. (1987) Torsion and bending analysis of internal fixation techniques for femoral neck fractures: the role of implant design and bone density. J Orthop Res. 1987; 5(3):433-444. [PubMed]

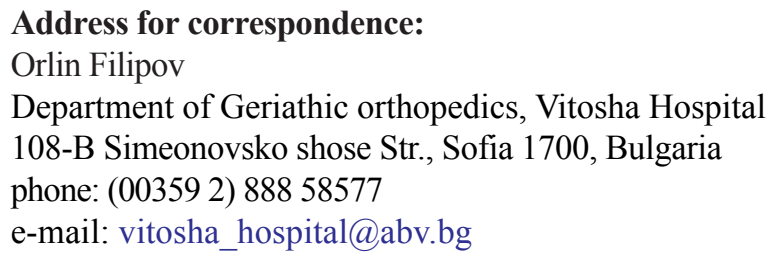

